\section{REFERENCES}

1. Chapman S. Over our dead bodies: gun law reform after Port Arthur. Annandale, NSW: Pluto Press, 1997.

2. National Injury Surveillance Unit, Adelaide, at www.nisu.flinders.edu.au/data/phonebook/queries/guns.php.

3. Australian Institute of Criminology. Homicide in Australia, 1989-96 at www.aic.gov.au/publications/rpp/13/RPP13.pdf.
4. Australian Institute of Criminology. Homicide in Australia, 1999-00 at www.aic.gov.au/research/hmonitor/stats/ genderv.html.

5. Australian Institute of Criminology. Homicide in Australia, 2000-01 at www.aic.gov.au/publications/rpp/40/ RPP40tables.pdf.

6. Cantor C. Drop in Suicide rates for 1999 at www.aifs.org.au/ ysp/pubs/bull5cc.pdf.

\title{
BUILDING THE INFRASTRUCTURE FOR PUBLIC HEALTH
}

\section{Sue Morey}

Chief Health Officer (1988-1994)

NSW Department of Health

\section{Lynne Madden \\ Public Health Training and Development Branch NSW Department of Health}

'Success' in public health is facilitated by the ability to attract and retain a well-trained and enthusiastic workforce and a suitable, stable infrastructure. This article briefly describes steps taken at the end of the 1980s both to determine the need for and to create a public health infrastructure and workforce for NSW. These initiatives have contributed to the continuing development of a robust and dynamic public health community that has demonstrated its capacity to respond to a wide variety of challenges.

\section{EARLY DEVELOPMENTS OF PUBLIC HEALTH IN NSW}

By the end of the nineteenth century, all the colonies of Australia had passed public health acts following the example of Britain where the first Public Health Act was passed in 1848. In NSW, under the Public Health Act of 1896 , the profile of public health fluctuated over the years.

During the 1980s, despite the emergence of the New Public Health, ${ }^{1}$ and national initiatives to promote public health training and research, the attention given to the public health infrastructure in NSW and to the training of a public health workforce had not paralleled that directed towards the public hospital system. Public health had a low profile, and positions previously devoted to public health activities had been redirected towards the management of the public hospital system.

\section{CREATION OF AREA HEALTH SERVICES}

In 1986, area-based health services were created in metropolitan NSW by the Area Health Services Act. ${ }^{2}$ In a fundamental change, the board of directors of each area health service (AHS) was made responsible not only for the management of the acute health care facilities in their areas but also for the protection, promotion and maintenance of the health of its resident population. Previously they had no formal responsibility for the health of their resident population.

Despite these broader responsibilities, most AHSs continued to place the greatest emphasis on the management and delivery of high quality clinical services through their facilities. A Department of Public Health and Community Medicine at Westmead Hospital had by the late 1980s developed a capacity in public health research and evaluation. However this facility was unique and generally there were few health professionals with the necessary skills to plan for the health of populations.

Several developments were initiated by the NSW Department of Health around this time to change this situation. In 1988 the newly appointed Chief Health Officer made the revitalisation of the public health infrastructure in NSW one of her priorities. The initial steps were the appointment of Medical Officers of Health in each area health service and rural region, and the creation of an Epidemiology Branch within the Department.

The value of effective public health action in response to acute health problems was soon demonstrated in the efficient management of outbreaks of communicable disease. Early in 1989, the Secretary of the Department invited a proposal to expand the use of epidemiology to underpin public health across the state.

Two proposals were developed. Under the first proposal, the new Epidemiology Branch would be expanded and an organisational structure inspired by that of the United States Centers for Disease Control and Prevention (CDC) adopted. This structure included units for Infectious Disease, Chronic Disease and Injury Control, 
Reproductive Health, Environmental Health and Health Informatics. There were three elements to the second proposal:

- a network of public health units would be established in the administrative health areas to decentralise public health functions;

- a public health officer training program would be established to provide training in the practical skills required for public health action;

- a mechanism for communicating public health information would be created, the NSW Public Health Bulletin, in the form of the Morbidity and Mortality Weekly Report published by the CDC.

In November 1989, a structural reorganisation within the NSW Department of Health led to the formation of the Public Health Division, and in December 1989 the Minister for Health approved annual funding to support the second proposal.

\section{PUBLIC HEALTH UNITS}

Fourteen public health units (PHUs) were established in the metropolitan AHSs and the rural regions, each to be led by a director who also served as the medical officer of health. The initial terms of reference were broad. Responsibilities included:

- coordinating all public health activity;

- research and evaluation;

- developing a public health strategy including surveillance;

- the analysis of local health related databases including hospital morbidity collections.

Other areas of responsibility were the control of communicable diseases, environmental health, the investigation of pregnancy outcomes, injury, chronic diseases, and risk factor prevalence. The PHUs concentrated initially on implementing a new communicable disease reporting and response system, which was supported by a laboratory surveillance system. This was introduced following a successful pilot in the Eastern Sydney AHS and complemented notifications of diseases received from medical practitioners.

\section{NSW PUBLIC HEALTH BULLETIN}

The first issue of the NSW Public Health Bulletin was published in May 1990, to facilitate the dissemination of timely public health information across the network of PHUs, and to other interested individuals and organisations. ${ }^{3}$ It has been in continuous production since.

\section{NSW PUBLIC HEALTH OFFICER TRAINING PROGRAM}

The NSW Public Health Officer Training Program was initiated in 1990. It was designed to develop the practical skills of people who had already completed postgraduate studies in public health. The Program was initially established to train medical graduates who would progress towards Fellowship of the newly-created Australasian Faculty of Public Health Medicine. In its first year, six public health medicine registrars were appointed and funding was also provided for a trainee to participate in the United States CDC Epidemic Intelligence Service. By its second year, the Program was expanded to include nonmedical trainees.

\section{CONCLUSION}

The PHUs, the NSW Public Health Officer Training Program, and the NSW Public Health Bulletin are today integral parts of the health system. With the creation of rural area health services in $1996,{ }^{4}$ PHUs became part of each area health service in NSW. In 1998, when the Corrections Health Service was formed, the number of PHUs reached 17. This network of PHUs permits coordination of many essential public health functions across the state. The NSW Public Health Officer Training Program has provided a skilled workforce able to fill a wide variety of public health functions including those encompassed by the PHUs. It has also served as a model for training programs in other states, such as Western Australia, and for other disciplines in public health, such as the NSW Biostatistical Officer Training Program. The Bulletin is now indexed on Medline and Index Medicus.

The need for a strong public health capacity remains as great today as it was in 1988 . However if continued gains are to be made in public health, public health training and infrastructure must remain relevant and capable of adapting to changing environments.

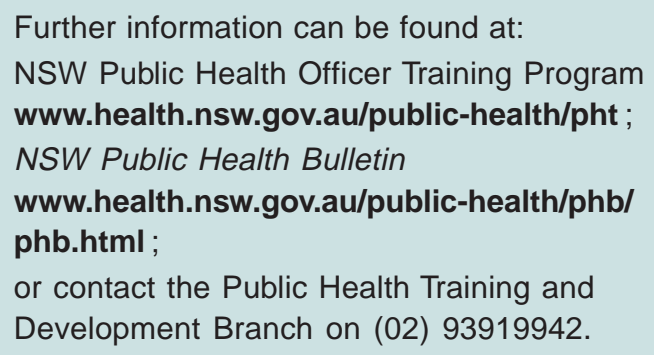

\section{REFERENCES}

1. Ashton J, Seymour H. The new public health. The Liverpool experience. Milton Keynes: Open University Press, 1988.

2. NSW Department of Health. Area Health Services. Sydney: Department of Health, 1986.

3. NS W Public Health Bull May 1990; 1(1).

4. NSW Department of Health. A vision for rural health. Sydney: NSW Department of Health, 1996. 